Two letters to the Editor re:

\title{
Lung deposition of budesonide from Turbuhaler@ is twice that from a pressurized metered-dose inhaler (P-MDI).
}

\author{
Thorsson, et al. Eur Respir J 1994 7: 1839-1844.
}

\section{To the Editor:}

In their article entitled "Lung deposition of budesonide from Turbuhaler® is twice that from a pressurized metered-dose inhaler (P-MDI)", THORsson et al. [1], conclude that by administering budesonide via the Turbuhaler instead of the MDI, the same degree of asthma control can be achieved with a lower dose which, in turn, reduces the risk of undesired systemic effects. The implication is that the Turbuhaler performs better than MDIs in general, despite the lack of data from multiple-dose studies to support such an argument.

Data that have recently been generated by us using the Andersen Cascade Impactor may give a different explanation for the findings of THORSSON et al. [1]. We have compared the fine particle fraction dose (i.e. particles of $<6 \mu \mathrm{m}$ ) of the budesonide (Bud) MDI with fluticasone propionate (FP) MDI, and the data were as follows:

\begin{tabular}{lcc}
\hline Drug/Device & $\begin{array}{c}\text { \% of dose delivered } \\
\text { (ex-valve) }<6 \mu \mathrm{m}( \pm \text { SEM })\end{array}$ \\
\hline FP & $50 \mu \mathrm{g} \mathrm{MDI}$ & $49( \pm 1.3)$ \\
Bud & $50 \mu \mathrm{g}$ MDI & $29( \pm 1.3)$ \\
FP & $250 \mu \mathrm{g}$ MDI & $42( \pm 1.0)$ \\
Bud & $200 \mu \mathrm{g}$ MDI & $26( \pm 0.8)$ \\
\hline
\end{tabular}

These data are consistent with those of OLSSON [2] and demonstrate that the pharmaceutical performance of the budesonide MDI is quite different from the fluticasone propionate MDI and, indeed, the budesonide Turbuhaler. This difference in pharmaceutical performance of the budesonide MDI could explain the findings of THORSSON et al. [1]. The above data also demonstrate that data for the budesonide MDI cannot be extrapolated more generally to other MDIs.

It is likely that these differences in fine particle fraction will only be of relevance in single-dose studies in volunteers, where a two-fold difference in particle size can be detected. In multiple-dose studies in patients, the much greater variability in drug delivered to the lung up to 10 fold between patients, will negate any differences seen in single-dose studies. In addition, the increased deposition, as reflected by the fine particle fraction, tends to be in the more peripheral part of the lung and neither $\beta$-agonists nor inhaled steroids, when used to treat asthma, are efficacious when landing in peripheral airways.
Therefore, any differences in lung deposition need to be supported by clinical data to determine whether they are clinically relevant. Indeed, there are data which show no difference, in terms of improvements in lung function, between the MDI and Turbuhaler in multiple-dose studies with ipatropium bromide [3], terbutaline $[4,5]$ and budesonide [6] as well as single-dose and cumulative dose studies with terbutaline $[7,8]$.

It is clear, therefore, that caution has to be taken in the interpretation of the clinical relevance of lung deposition studies, both in terms of extrapolation to other drugs in the same device and also different drugs and devices.

\section{References}

1. Thorsson L, Edsbäcker S, Conradson T-B. Lung deposition of budesonide from Turbuhaler ${ }^{\circledR}$ is twice that from a pressurized metered-dose inhaler, P-MDI. Eur Respir $J$ 1994; 7: 1839-1844.

2. Olsson B. Aerosol particle generation from dry powder inhlaers: can they equal pressurized metered-dose inhalers. J Aerosol Medicine 1995; 8: 513-519.

3. Bollert FGE, Matusiewicz SP, Dewar M, et al. Comparative efficacy of ipratropium bromide via Turbuhaler® and MDI in patients with reversible airflow obstruction. Thorax 1995; 50(4): 469P.

4. Hultquist C, Ahlström H, Kjellman NIM, et al. A doubleblind comparison between a new multi-dose powder inhaler (Turbuhaler ${ }^{\circledR}$ ) and metered-dose inhaler in children with asthma. Allergy 1989; 44: 467-470.

5. Osterman K, Norborg AM, Stähl E, et al. A multi-dose powder inhaler (Turbuhaler $\left.{ }^{\circledR}\right)$ compared with a conventional aerosol. Allergy 1989; 44: 294-297.

6. Hetta L, Larsson LG, Nikander K, et al. A comparative clinical study of inhaled budesonide delivered either via a pressurized metered-dose inhaler or via Turbuhaler@. Eur Respir J 1989; 2: 832S.

7. Svenonius E, Arborelius M, Wiberg R, et al. A comparison of trebutaline inhaled by Turbuhaler@ and by a chloroflourocarbon (CFC) inhaler in children with exerciseinduced asthma. Allergy 1994; 49: 408-412.

8. Johnsen CR, Weeke ER. Turbuhaler®: A new device for dry powder terbutaline inhalation. Allergy 1988; 43: 392-395.

R.W. Fuller, R.K. Sharma, A. Cripps

Glaxo Research and Development Ltd, Stockley Park West, Uxbridge, Middlesex UB11 1BT, UK. 


\section{Advantage of breath-actuated inhalers versus metered-dose inhalers}

\section{To the Editor:}

In a recent paper, THORSSON et al. [1] reported the results of an experimental comparison of lung deposition of budesonide from Turbuhaler ${ }^{\circledR}$ and from a pressurized metered-dose inhaler (MDI). The administration of budesonide via Turbuhaler® gave rise to a lung deposition which was approximately twice that of a MDI, with less variability. The authors suggested that a less wellcontrolled inhalation procedure than that used in their study could have resulted in a greater difference between the two devices. This suggestion is confirmed by clinical studies showing that breath-actuated inhalers are used more correctly than MDIs [2, 3].

These results are particularly crucial, since drug administration by inhalation is currently the most widespread treatment for asthma, MDIs are the most popular inhalation devices to administrate these drugs, and their misuse is frequent, both in hospitalized [4] and in private practice patients. In a recent study, we assessed the frequency of, and factors related to, misuse of MDIs in asthmatic patients of French private practice [5].

Two hundred and sixty four chest specialists or general practitioners completed questionnaires for three consecutive asthmatic patients aged $>6$ yrs and currently using MDIs: 668 adults (aged $48 \pm 19$ yrs, 52\% males) and 100 children (aged 12 \pm 2 yrs, $72 \%$ males) were included. Patients demonstrated how they used the MDI. Adequate technique (deep inspiration synchronized with inhaler activation, followed by breath holding for $5 \mathrm{~s}$ ) was used by $33 \%$ of adults and $26 \%$ of children; optimal technique (same, plus shaking the inhaler before use and activating it only once) was used by $22 \%$ of adults and $20 \%$ of children. The questionnaires also included questions on the characteristics of patients (sex, age, educational level, smoking habits, and size of the town of residence); characteristics of asthma (frequency of attacks, history of hospitalizations for asthma, impact of asthma on daily life, and treatment); and any previous instruction in the use of inhalers. Previous instruction was the factor most closely correlated with correct use. However, among adults that received instruction in the use of inhalers, only $39 \%$ applied adequate technique and $27 \%$ optimal technique.

Since the problems related to instruction in the use of MDIs and to its lack of effectiveness in the long-term have not been solved, the improvement of drug delivery might be achieved by using dry powder breath-actuated inhalers.

\section{References}

1. Thorsson L, Edsbäcker S, Conradson T-B. Lung deposition of budesonide from Turbuhaler ${ }^{\circledR}$ is twice that from a pressurized metered-dose inhaler, P-MDI. Eur Respir $J$ 1994; 7: 1839-1844.

2. Newman SP, Weisz AWB, Talaee N, Clarke SW. Improvement of drug delivery with a breath actuated pressurised aerosol for patients with poor inhaler technique. Thorax 1991; 46: 712-716.

3. Chapman KR, Love L, Brubaker H. A comparison of breath-actuated and conventional metered-dose inhaler inhalation techniques in elderly subjects. Chest 1993; 104: 1332-1337.

4. Thompson CJ, Irvine MT, Grathwohl CK, Roth MB. Misuse of metered-dose inhalers in hospitalized patients. Chest 1994; 105: 715-717.

5. Liard R, Zureik M, Aubier M, Korobaeff M, Henry, Neukirch F. Misuse of pressurized metered dose inhalers by asthmatic patients treated in French private practice. Rev Epidemiol Santé Publique 1995; 43: 242-249.

R. Liard, M. Aubier, M. Zureik, F. Neukirch

INSERM Unité 408, Faculté Xavier Bichat, Paris, France.

\section{REPLY}

\section{From the authors:}

We read with great interest the letters from LIARD et al. ("Advantage of breath-actuated inhalers versus metereddose inhalers") and from FULLER et al. commenting on our article "Lung deposition of budesonide from Turbuhaler® is twice that from a pressurized metereddose inhaler P-MDI" [1]. In our article, we concluded that the lung deposition of budesonide via Turbuhaler is approximately twice that of a P-MDI, with less variability. Turbuhaler gives a more favourable ratio of the contribution from pulmonary absorbed drug to the overall systemic availability, which indicates that the same degree of asthma control can be achieved with a lower dose than from the P-MDI. We also cited clinical studies where this has been confirmed $[2,3]$.
The difficulties in handling a P-MDI optimally is a well-known problem $[4,5]$. The study summarized by LIARD et al. in the accompanying letter to the editor, confirms the abundant misuse of P-MDIs, with only $38.6 \%$ of the asthmatic patients being able to use an adequate technique. The authors arrive at the same conclusion as we did in our paper, i.e. improvement of drug delivery might be achieved by using dry powder breath-actuated inhalers.

Dr Fuller and colleagues, in their letter, seem to agree with this conclusion but suggest that differences in the fine particle fraction dose might explain the difference in lung deposition obtained between Turbuhaler and P-MDI. They also supply data indicating that the fraction of fine particles $(<6 \mu \mathrm{m})$ is larger for fluticasone P-MDI than for budesonide P-MDI. They claim, however, that the fine particle fraction of the dose does not contribute to the clinical efficacy of the drug, as it is expected to be 
deposited too peripherally to elicit the desired topical effect. If Dr Fuller and colleagues are correct in their hypothesis, the fluticasone P-MDI formulation would be expected to give a less favourable risk-benefit ratio, as the fine particle fraction not contributing to the desired antiasthma effect should still be expected to give undesired systemic effects.

We are, however, unaware of the evidence showing that the fine particle fraction does not contribute to the overall anti-asthma effect. On the contrary, budesonide Turbuhaler has a higher fine particle dose than budesonide P-MDI and evidence of a better clinical effect $[2,6]$. If the fine particle fraction contributes to the clinical effect of the drug, and as budesonide and fluticasone have been shown to be approximately equipotent topically [7], budesonide Turbuhaler as well as fluticasone P-MDI would perform better than budesonide P-MDI. This seems indeed to be the case, as suggested by studies from Ayres et al. [8], LANGDON and THOMPSON [9], AgERTOFT and Pedersen [2] and ENgel et al. [10]. The last two studies are multiple-dose studies comparing the effect of budesonide Turbuhaler with budesonide P-MDI. The claim by Dr Fuller and colleagues, that such data are lacking is, thus, not correct. There is also strong evidence of a good correlation between deposition data and clinical effect for several anti-asthma drugs: there is an approximate 2:1 relationship to P-MDI formulations both in deposition and clinical efficacy for terbutaline Turbuhaler $₫$, salbutamol Turbuhaler®, and ipratropium bromide Turbuhaler® [11-13].

Finally, as agreed by Fuller and colleagues in their letter, each system of drug and inhaler should be regarded as a separate entity, with unique properties regarding therapeutic potency and side-effects. Our article specifically discusses budesonide P-MDI and budesonide Turbuhaler and does not make any claims about Turbuhaler performing better than P-MDIs in general. Hence, each combination of drug and inhaler should be documented separately in well-designed studies. Unfortunately, clinical studies of suboptimal design are sometimes used to compare inhaled steroids. With a shallow dose-response relationship, two different doses of the same drug may give similar effects in such studies. Thus, in trials where the outcome is "no difference", the conclusions could have been predetermined by the doses chosen in the study design. Well-controlled single-dose studies can never replace well-designed, multiple-dose, doubleblind clinical studies, but may be very useful in the interpretation of clinical findings and also to form a bridge between in vitro performance of a pharmaceutical formulation and its clinical properties.

\section{References}

1. Thorsson L, Edsbäcker S, Conradson T-B. Lung deposition of budesonide from Turbuhaler is twice that from a pressurized metered-dose inhaler, P-MDI. Eur Respir J 1994; 7 : 1839-1844.

2. Agertoft L, Pedersen S. Importance of inhalation device on the effect of budesonide. Arch Dis Child 1993; 69: 130133.

3. Selroos O, Backman R, Forsén KO, et al. Clinical efficacy of budesonide Turbuhaler® compared with that of beclomethasone dipropionate pMDI with Volumatic spacer: a 2 year randomized study in 102 patients. Allergy 1994; 49: 833-836.

4. Crompton GK. Problems patients have using pressurized aerosol inhalers. Eur J Respir Dis 1982; 63: 101-104.

5. Goodman DE, Israel E, Rosenberg M, Johnston R, Weiss ST, Drazen JM. The influence of age, diagnosis, and gender on proper use of metered-dose inhalers. Am J Crit Care Med 1994; 150: 1256-1261.

6. Olsson B. Aerosol particle generation from dry powder inhalers: can they equal pressurized metered dose inhalers. $J$ Aerosol Medicine, (Accepted for publication.)

7. Andersson N, Klint S, Randwall G, Wirén JE. Equipotency of budesonide and fluticasone propionate in the vasoconctriction assay. Am J Crit Care Med 1994; 149 (4, pt 2): A467.

8. Ayres JG, Bateman ED, Lundbäck B, Harris TA. High dose fluticasone propionate, $1 \mathrm{mg}$ daily, versus fluticasone propionate, $2 \mathrm{mg}$ daily, or budesonide, $1.6 \mathrm{mg}$ daily, in patients with chronic severe asthma. Eur Respir J 1995; 8: 579-586.

9. Langdon CG, Thompson J. A multicentre study to compare the efficacy and safety of inhaled fluticasone propionate and budesonide via metered-dose inhalers in adults with mild-to-moderate asthma. Br J Clin Res 1994; 5: 73-84.

10. Engel T, Heinig JH, Malling HJ, Scharling B, Nikander K, Madsen F. Clinical comparison of inhaled budesonide delivered either via pressurized metered dose inhaler or Turbuhaler ${ }^{\circledR}$. Allergy 1989; 44: 220-225.

11. Derom E, Wåhlin-Boll E, Borgström L, Pauwels R. Pulmonary deposition and effect of terbutaline administered by metered-dose inhaler or Turbuhaler. Thorax 1994, 49: A402.

12. Löfdahl CG, Arvidsson P, Bondesson E, Friberg K. Higher potency of salbutamol when given via Turbuhaler than via pressurized metered dose inhaler (pMDI). Allergy Clin Immunol News 1994; 6 (Suppl. 2): 383.

13. Matusiewicz SP, Bollërt FGE, Dewar M, et al. Ipratropium bromide given by Turbohaler $₫$ is more potent than when given by pressurised metered-dose inhaler (MDI). Thorax 1995; 50(4): 469.

\section{Thorsson, S. Edsbäcker}

Clinical Research and Development, Astra Draco AB, Lund, Sweden. 